\title{
Ninety-day mortality after resection for lung cancer is nearly double 30-day mortality
}

\author{
Christopher M. Pezzi, MD, ${ }^{\mathrm{a}}$ Katherine Mallin, PhD, ${ }^{\mathrm{b}}$ Andres Samayoa Mendez, MD, \\ Emmelle Greer Gay, $\mathrm{PhD},{ }^{b}$ and Joe B. Putnam, Jr, $\mathrm{MD}^{\mathrm{c}}$
}

Objective: To evaluate 30-day and 90-day mortality after major pulmonary resection for lung cancer including the relationship to hospital volume.

\begin{abstract}
Methods: Major lung resections from 2007 to 2011 were identified in the National Cancer Data Base. Mortality was compared according to annual volume and demographic and clinical covariates using univariate and multivariable analyses, and included information on comorbidity. Statistical significance $(P<.05)$ and $95 \%$ confidence intervals were assessed.

Results: There were 124,418 major pulmonary resections identified in 1233 facilities. The 30-day mortality rate was $2.8 \%$. The 90 -day mortality rate was $5.4 \%$. Hospital volume was significantly associated with 30 -day mortality, with a mortality rate of $3.7 \%$ for volumes less than 10 , and $1.7 \%$ for volumes of 90 or more. Other variables significantly associated with 30-day mortality include older age, male sex, higher stage, pneumonectomy, a previous primary cancer, and multiple comorbidities. Similar results were found for 90-day mortality rates. In the multivariate analysis, hospital volume remained significant with adjusted odds ratios of 2.1 (95\% confidence interval [CI], 1.7-2.6) for 30-day mortality and $1.3(95 \% \mathrm{CI}, 1.1-1.6)$ for conditional 90-day mortality for the hospitals with the lowest volume $(<10)$ compared with those with the highest volume (>90). Hospitals with a volume less than 30 had an adjusted odds ratio for 30-day mortality of 1.3 (95\% CI, 1.2-1.5) compared with those with a volume greater than 30 .
\end{abstract}

Conclusions: Mortality at 30 and 90 days and hospital volume should be monitored by institutions performing major pulmonary resection and benchmarked against hospitals performing at least 30 resections per year. (J Thorac Cardiovasc Surg 2014;148:2269-78)

See related commentary on page 2279 .

Hospital volume has been repeatedly associated with the outcome after specific complex surgical resections since first reported by Luft and colleagues in 1979. ${ }^{1}$ The purpose of this study was to determine the relationship between hospital volume and outcome and to identify predictors of improved outcome after major pulmonary resection for cancer at 30 days, 90 days, and between 30 days and 90 days (conditional 90-day mortality) postoperatively using the National Cancer Data Base (NCDB). We hypothesized that overall 90-day mortality after a lung resection would

From the Department of Surgery, ${ }^{\text {a }}$ Abington Health, Abington, Pa; American College of Surgeons, ${ }^{\mathrm{b}}$ Commission on Cancer, Chicago, Ill; and Department of Thoracic Surgery, ${ }^{\mathrm{c}}$ Vanderbilt University Medical Center, Nashville, Tenn.

Disclosures: Joe B. Putnam Jr. reports lecture fees from Covidien. All other authors have nothing to disclose with regard to commercial support.

Read at the 94th Annual Meeting of The American Association for Thoracic Surgery, Toronto, Ontario, Canada, April 26-30, 2014.

Received for publication April 9, 2014; revisions received July 9, 2014; accepted for publication July 20, 2014; available ahead of print Aug 27, 2014

Address for reprints: Christopher M. Pezzi, MD, Department of Surgery, Abington Health, Price Medical Office Building, 1245 Highland Ave, Suite 604, Abington, PA 19001 (E-mail: cpezzi@abingtonhealth.org).

$0022-5223 / \$ 36.00$

Copyright (c) 2014 by The American Association for Thoracic Surgery

http://dx.doi.org/10.1016/j.jtcvs.2014.07.077 be significantly higher than 30-day operative mortality, and that a volume/outcome relationship would persist. Using the NCDB, the American College of Surgeons (ACoS) Commission on Cancer (CoC) has the ability to directly report individual annual volume and mortality data to more than 1500 cancer programs, and to allow programs to compare their data to all CoC-accredited programs in the United States.

\section{METHODS}

The NCDB is a joint project of the ACoS CoC and the American Cancer Society and captures data from approximately $70 \%$ of all new cancers in the United States treated at approximately 1500 facilities, including $82 \%$ of all lung cancers. ${ }^{2}$ Institutional review board approval was not required. Lung cancer cases diagnosed from 2007 to 2011 were retrieved from the database. Selection criteria included age 18 years or older and having had a surgical resection in the reporting facility. Lobectomies, bilobectomies, and pneumonectomies were included, but not wedge resections or other resections of less than 1 lobe.

There were 124,418 lung resections identified in 1233 facilities from 2007 to 2011 using the selection criteria. There were 2 hospitals with $40 \%$ or more of cases missing 30-day mortality and 4 hospitals with $40 \%$ or more of cases missing 90-day mortality. Excluding these hospitals resulted in the exclusion of 17 cases for 30-day mortality and 129 cases for 90-day mortality. An additional 3300 cases missing 30-day mortality regardless of hospital were also excluded, resulting in 121,099 cases available for analysis in 1231 hospitals. Overall, $95 \%$ of hospitals were missing 30-day mortality for less than $10 \%$ of cases and $86 \%$ of hospitals were missing 30 -day 


\section{Abbreviations and Acronyms \\ $\mathrm{ACoS}=$ American College of Surgeons \\ $\mathrm{CI}=$ confidence intervals \\ $\mathrm{CoC}=$ Commission on Cancer \\ $\mathrm{NCDB}=$ National Cancer Data Base \\ NIS = Nationwide Inpatient Sample \\ SEER = Surveillance, Epidemiology, and End Results}

mortality for less than $5 \%$ of cases. After excluding 3389 deaths within 30 days and cases missing 90-day mortality, there were 114,905 cases available for analysis to assess conditional 90-day mortality (Figure 1).

Demographic and clinical characteristics of the analytical cases are reported in Table 1 . The mean age was 66.6 years; $42 \%$ of patients were aged 70 years or older.

Ninety-three percent of resections were lobectomies or bilobectomies and $7 \%$ were pneumonectomies. Nine percent of resections were performed in hospitals with an annual surgical volume of less than 10 cases a year, and $11 \%$ were performed in hospitals with more than 90 resections a year. The median annual volume for all resections was 33 cases per year. Sixty-two percent of cases were stage 0 , I, or occult, and $34 \%$ were stage II or III. Twenty-four percent had 1 or more previous primary tumors (sites unknown). Six percent of patients received neoadjuvant chemotherapy and $2 \%$ received neoadjuvant radiation.

Mortality within 30 and 90 days of the definitive surgery date was determined, as well as mortality between 31 and 90 days from definitive surgery (conditional 90-day mortality). Annual hospital volume was determined by taking the average number of lung resections performed from 2007 to 2011. Initially, 6 annual volume groups were examined: less than 10,10 to 19,20 to 29,30 to 39,40 to 89 , and more than 90 resections per year. Only currently accredited $\mathrm{CoC}$ hospitals were included, and hospitals were required to have reported cancer cases each year between 2007 and 2011. Hospitals with $40 \%$ or more of cases missing 30- or 90-day mortality were excluded (because of incomplete follow-up).

Demographic and clinical covariates were used in the univariate and multivariable analyses. Mortality rates were similar for hospital volumes between 10 and 29 and between 30 and 89 , so 4 volume groups (0-9, $10-29,30-89$ and $\geq 90$ ) were used in the bivariate and multivariate analyses. NCDB comorbidity information is derived from up to 10 ICD-9-CM codes recorded for each patient. These codes are used to categorize 28 Elixhauser comorbidity groups, ${ }^{3}$ which have been found to be a better predictor of outcomes than the Charlson Comorbidity Index. ${ }^{4,5}$ Patient income level was not available but was determined from the zip code of residence and the 2000 US Census Bureau median income for that zip code. Patient residence was also categorized by census division.

\section{Statistical Analyses}

Overall 30- and 90-day mortality by annual hospital volume was calculated. Because overall 90-day mortality includes deaths that occur in the first 30 days, conditional 90-day mortality was calculated by excluding deaths occurring within the first 30 days from definitive surgery. Factors independently associated with mortality after 30 days can then be evaluated using conditional 90-day mortality.

Thirty-day and conditional 90-day mortality were compared according to annual hospital volume and demographic and clinical characteristics. Statistical significance $(P<.05)$ and $95 \%$ confidence intervals $(\mathrm{CI})$ were assessed using survey sampling methodology to account for clustering at the hospital level. Multivariate analysis was conducted using a hierarchical regression model that include a random effects model to account for patient clustering within hospitals, using the GLIMMIX procedure in SAS (SAS version 9.4, SAS Institute, Inc, Cary, NC). Variables in the model included all those that were significantly associated with either 30-day or conditional 90-day mortality in the bivariate analyses.

\section{RESULTS}

In the first 30 days after definitive surgery, 3389 deaths occurred, resulting in a 30-day mortality rate of $2.8 \%$ (95\% CI, 2.7-2.9). A total of 6353 deaths occurred within the first 90 days, resulting in an overall 90-day mortality of $5.4 \%$ (95\% CI, 5.2-5.6). After excluding the deaths in the first 30 days, the conditional 90-day mortality was $2.6 \%$ (95\% CI, 2.5-2.7) based on 2968 additional deaths between 31 days and 90 days. Figure 2 displays the overall 30-day, conditional 90-day, and 90-day mortality by the 6 hospital volume groups. Figure 3 shows the overall 30-day, conditional 90-day, and 90-day mortality by 4 volume groups.

Thirty-day and conditional 90-day mortality and 95\% CIs by annual hospital volume and demographic/clinical variables are displayed in Table 2. Hospital volume is significantly associated with 30-day mortality, with a mortality of $3.7 \%$ for volumes less than 10 , and $1.7 \%$ for volumes of 90 or more. A small but significant decrease in 30-day mortality was found between 2007 and 2011. Other variables significantly associated with 30-day mortality include older age, male sex, lower median income, and living in the southern US regions. Other factors significantly associated with a higher 30-day mortality were higher stage, pneumonectomy, a previous primary cancer, and neoadjuvant radiation. Multiple comorbidities were significantly associated with higher 30-day mortality; lower 30-day mortality was associated with 5 comorbidities (see Table 2).

Similar results were found for conditional 90-day mortality. Annual hospital volume was significantly associated with conditional 90-day mortality although smaller differences were found compared with 30-day mortality. For the lowest hospital volume group, the 90-day conditional mortality rate was $2.9 \%$ compared with $2.2 \%$ in the highest volume group. Significant associations were also found with diagnosis year, age, sex, race, insurance status, and census division. Clinical variables significantly associated with conditional 90-day mortality include stage, surgery type, having a previous cancer, and having had neoadjuvant radiation and neoadjuvant chemotherapy. Comorbid conditions significantly associated with conditional 90-day mortality were similar to those for 30-day mortality.

Multivariate adjusted odds ratios are displayed in Table 3. Annual hospital volume remained significantly associated with 30-day mortality with an adjusted odds ratio of 2.1 (95\% CI, 1.7-2.6), and with conditional 90-day mortality with an adjusted odds ratio of 1.3 (95\% CI, 1.1-1.6) for the lowest compared with the highest hospital volume. The adjusted odds ratio for 30-day mortality was 1.3 (95\% CI, 1.2-1.5) for hospitals with annual volume less than 30 compared with those with an annual volume greater 


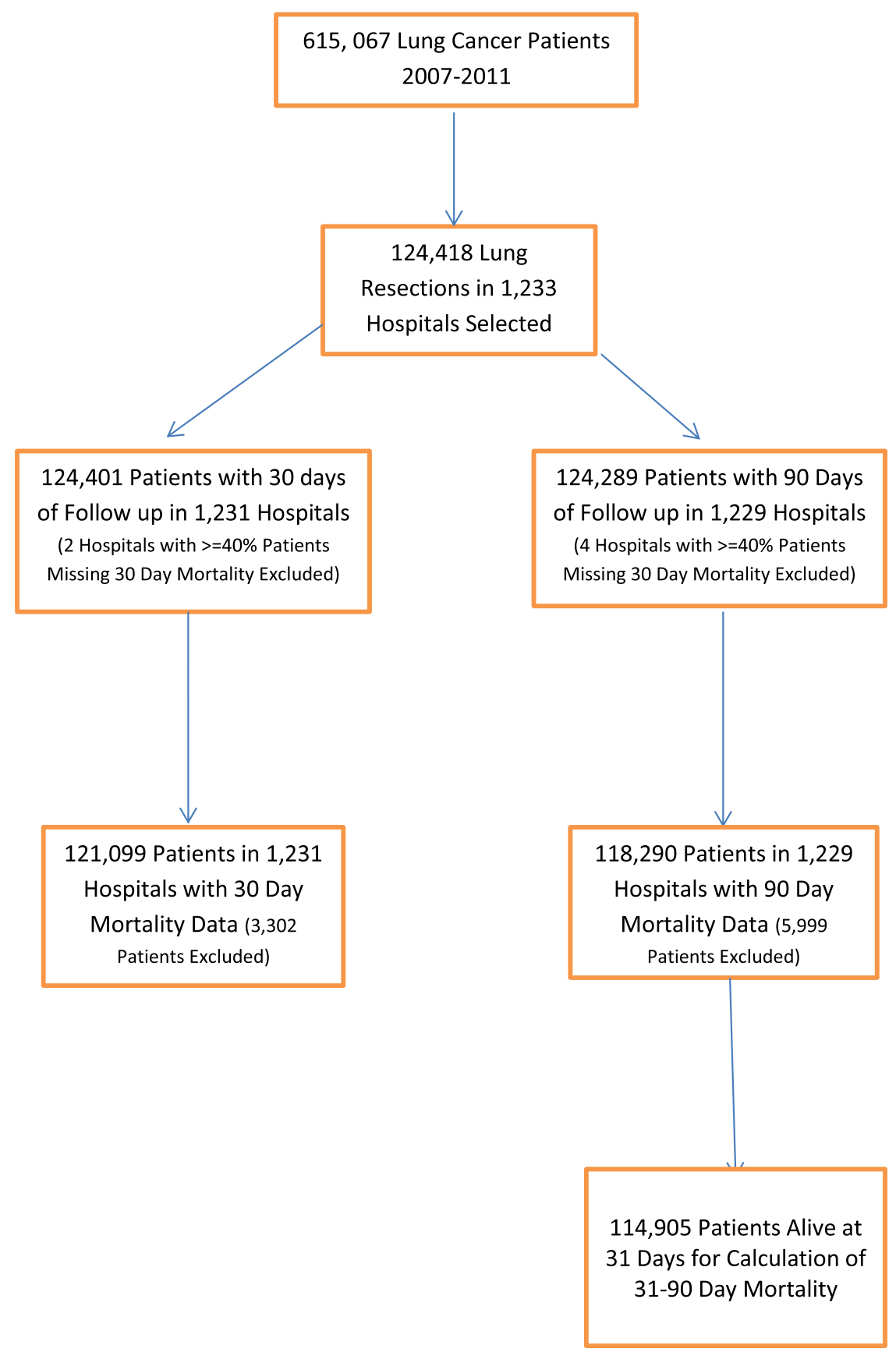

FIGURE 1. Cohort selection examining mortality at 30 days and 90 days after major pulmonary resection for cancer from 2007 to 2011 in the National Cancer Data Base.

than 30. Demographic variables remained significantly associated with 30- and 90-day conditional mortality, with the exception of race/ethnicity, which was not significantly associated with 30-day mortality. Stage and surgery type were significantly associated with 30-day and 90-day conditional mortality.

Table 4 includes mortality rates for lobectomies and bilobectomies versus pneumonectomies. Significant associations with annual hospital volume for lobectomy/bilobectomy were found for both 30-day and conditional 90-day mortality. For pneumonectomies, hospital volume was also significantly associated with 30-day mortality but not 90-day conditional mortality.

Evaluation of the potential effect of the 3317 cases excluded for missing 30-day mortality information revealed a similar distribution by annual hospital volume for these excluded cases, with $2.5 \%, 2.9 \%, 2.5 \%$, and $2.6 \%$ of those with annual hospital volume of less than 10,10 to 29,30 to 
TABLE 1. Demographic and clinical percentage distribution of lung cancer resections, 2007 to $2011(n=121,099)$

\begin{tabular}{|c|c|c|}
\hline & $\begin{array}{l}\text { Percentage } \\
\text { distribution }\end{array}$ & Number of cases \\
\hline \multicolumn{3}{|l|}{ Age } \\
\hline $18-49 \mathrm{y}$ & 5.9 & 7140 \\
\hline $50-59$ y & 17.5 & 21,207 \\
\hline $60-69$ y & 34.6 & 41,877 \\
\hline $70-79$ & 32.9 & 39,919 \\
\hline$\geq 80$ & 9.0 & 10,956 \\
\hline \multicolumn{3}{|l|}{ Race } \\
\hline White & 87.8 & 106,359 \\
\hline Black & 8.6 & 10,438 \\
\hline Other & 3.6 & 4302 \\
\hline \multicolumn{3}{|l|}{ Sex* } \\
\hline Male & 50.7 & 61,367 \\
\hline Female & 49.3 & 59,700 \\
\hline \multicolumn{3}{|l|}{ Insurance } \\
\hline Private, selfpay & 33.8 & 40,918 \\
\hline None, Medicaid & 5.0 & 6067 \\
\hline Medicare & 56.8 & 68,780 \\
\hline Other government & 3.2 & 3917 \\
\hline Unknown & 1.2 & 1417 \\
\hline \multicolumn{3}{|l|}{ Median income quintiles $\dagger$} \\
\hline$<$ US\$28,000 & 8.8 & 10,664 \\
\hline US $\$ 28,000-32,000$ & 13.1 & 15,820 \\
\hline US $\$ 33,000-38,000$ & 18.5 & 22,422 \\
\hline US $\$ 39,000-48,000$ & 23.1 & 28,034 \\
\hline$\geq \mathrm{US} \$ 49,000$ & 30.7 & 37,173 \\
\hline Unknown & 5.8 & 6986 \\
\hline \multicolumn{3}{|l|}{ Census division $\ddagger$} \\
\hline New England & 5.8 & 7075 \\
\hline Middle Atlantic & 15.0 & 18,112 \\
\hline South Atlantic & 22.5 & 27,301 \\
\hline East North Central & 19.3 & 23,410 \\
\hline East South Central & 8.5 & 10,329 \\
\hline West North Central & 7.3 & 8904 \\
\hline West South Central & 7.0 & 8532 \\
\hline Mountain & 3.9 & 4691 \\
\hline Pacific & 10.4 & 12,574 \\
\hline Out of United States & 0.1 & 171 \\
\hline \multicolumn{3}{|c|}{ Average annual hospital volume, lung resections } \\
\hline $0-9$ & 9.0 & 10,860 \\
\hline $10-19$ & 18.4 & 22,233 \\
\hline $20-29$ & 17.5 & 21,176 \\
\hline $30-39$ & 11.7 & 14,227 \\
\hline $40-89$ & 32.1 & 38,928 \\
\hline$\geq 90$ & 11.3 & 13,675 \\
\hline \multicolumn{3}{|l|}{ Surgery type } \\
\hline Lobectomy/bilobectomy & 93.4 & 113,150 \\
\hline Pneumonectomy & 6.6 & 7949 \\
\hline \multicolumn{3}{|l|}{ Stage } \\
\hline $0, \mathrm{I}$, occult & 61.7 & 74,772 \\
\hline II & 19.6 & 23,702 \\
\hline III & 14.3 & 17,321 \\
\hline IV & 2.6 & 3156 \\
\hline Unknown & 1.8 & 2148 \\
\hline
\end{tabular}

TABLE 1. Continued

\begin{tabular}{lcc}
\hline & $\begin{array}{c}\text { Percentage } \\
\text { distribution }\end{array}$ & Number of cases \\
\hline Cancer sequence & & \\
$\quad$ Only or first primary & 75.9 & 91,868 \\
$\quad$ Second or higher primary & 24.1 & 29,231 \\
Neoadjuvant chemotherapy & & \\
$\quad$ No & 94.4 & 114,128 \\
$\quad$ Yes & 5.8 & 6971 \\
Neoadjuvant radiation & & \\
$\quad$ No & 98.0 & 118,681 \\
Yes & 2.0 & 2418 \\
\hline
\end{tabular}

*Excluding 32 cases, sex unknown or other. †Based on zip code level income from 2000 Census. $\ddagger$ Patient residence. Census region states include New England (Maine, Vermont, New Hampshire, Massachusetts, Connecticut, Rhode Island), Middle Atlantic (New York, Pennsylvania, New Jersey), South Atlantic (West Virginia, Maryland, Delaware, District of Columbia, Virginia, North Carolina, South Carolina, Georgia, Florida), East North Central (Wisconsin, Illinois, Michigan, Indiana, Ohio); East South Central (Kentucky, Tennessee, Mississippi, Alabama), West North Central (North Dakota, South Dakota, New England, Kansas, Minnesota, Iowa, Missouri), West South Central (Oklahoma, Arkansas, Louisiana, Texas), Mountain (Montana, Idaho, Wyoming, Nevada, Utah, Colorado, Arizona, New Mexico), Pacific (Washington, Oregon, California, Hawaii).

89 , and 90 or more excluded. Missing 30-day mortality data was much higher $(7.9 \%)$ for the final year of the study (2011) compared with the earlier 4 years $(0.8 \%-2.3 \%)$. The 30-day mortality observed for 2007 to 2010 (2011 data excluded) was $2.85 \%(95 \% \mathrm{CI}, 2.74-2.95)$, which was essentially the same as the $2.80 \% \quad(95 \% \mathrm{CI}$, 2.70-2.89) for all 5 years of the study, including 2011.

\section{DISCUSSION}

The current study has confirmed a relationship between hospital volumes of major pulmonary resection for cancer with 30-day mortality, and identified a statistically significant difference in 90-day conditional mortality based on annual hospital volume. In addition, a near doubling of the (30-day) mortality rate by 90 days after surgery was observed. The ongoing mortality between 31 and 90 days postoperatively was seen across all volume groups, not only in low volume groups, and warrants further study to identify the causes of this delayed mortality.

Numerous studies dealing with the relationship of hospital volume to operative mortality after resection of lung cancer have been published, ${ }^{6-14}$ In 1992, Romano and Mark $^{6}$ reported the outcome of 12,439 adults who underwent pulmonary resection through California hospital discharge abstracts between 1983 and 1986. Mortality was $4.2 \%$ after lobectomy and $11.6 \%$ after pneumonectomy. Multivariate regression models identified age greater than 60 years, male gender, extended resection, chronic lung or heart disease, diabetes, and hospital volume as risk factors for in-hospital mortality.

Bach and colleagues ${ }^{7}$ used the Surveillance, Epidemiology, and End Results (SEER) Cancer Registry linked to 


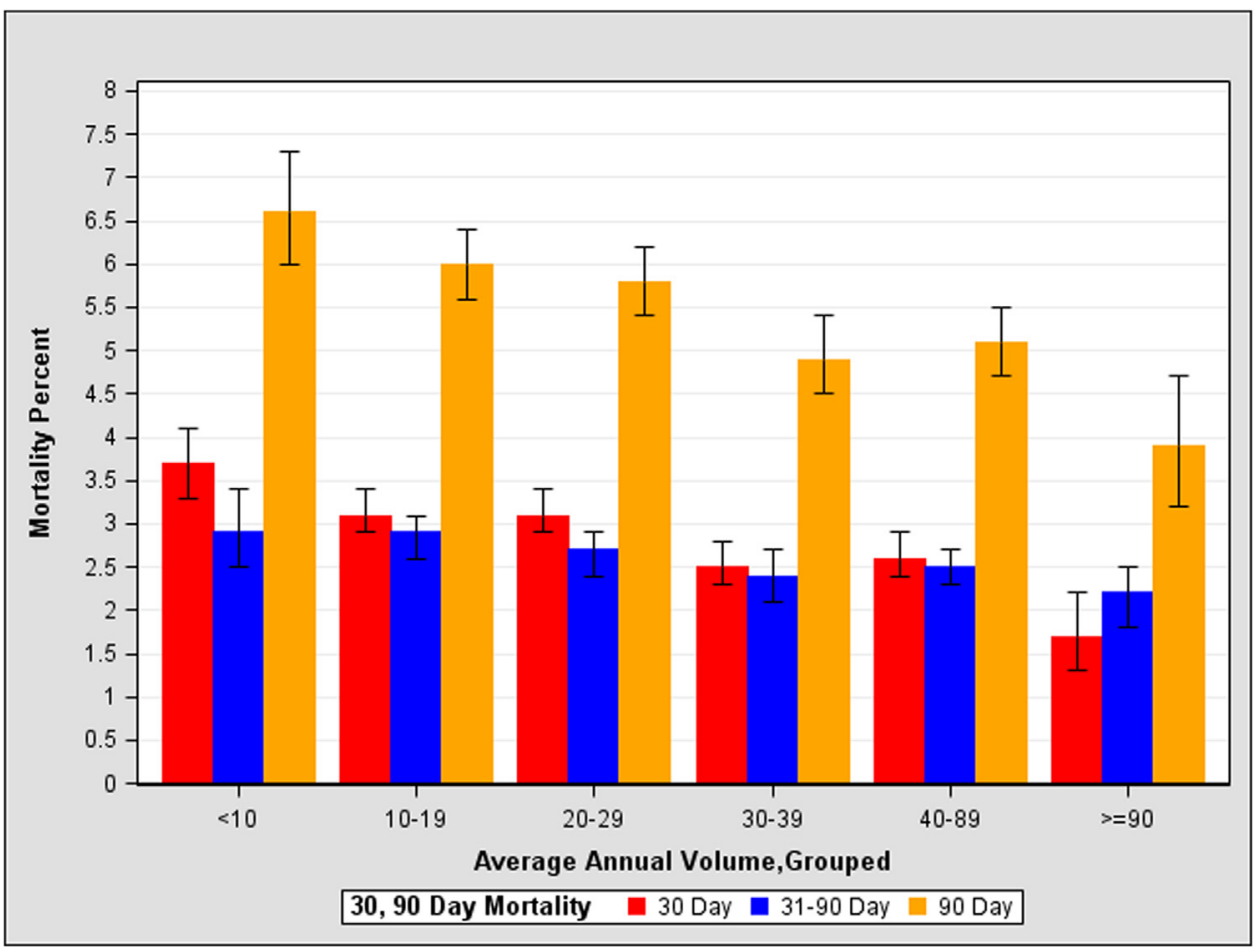

FIGURE 2. Thirty-day, conditional 90-day, and 90-day mortality rates, $95 \%$ confidence intervals, after major pulmonary resection by average annual hospital volume group (6 groups).

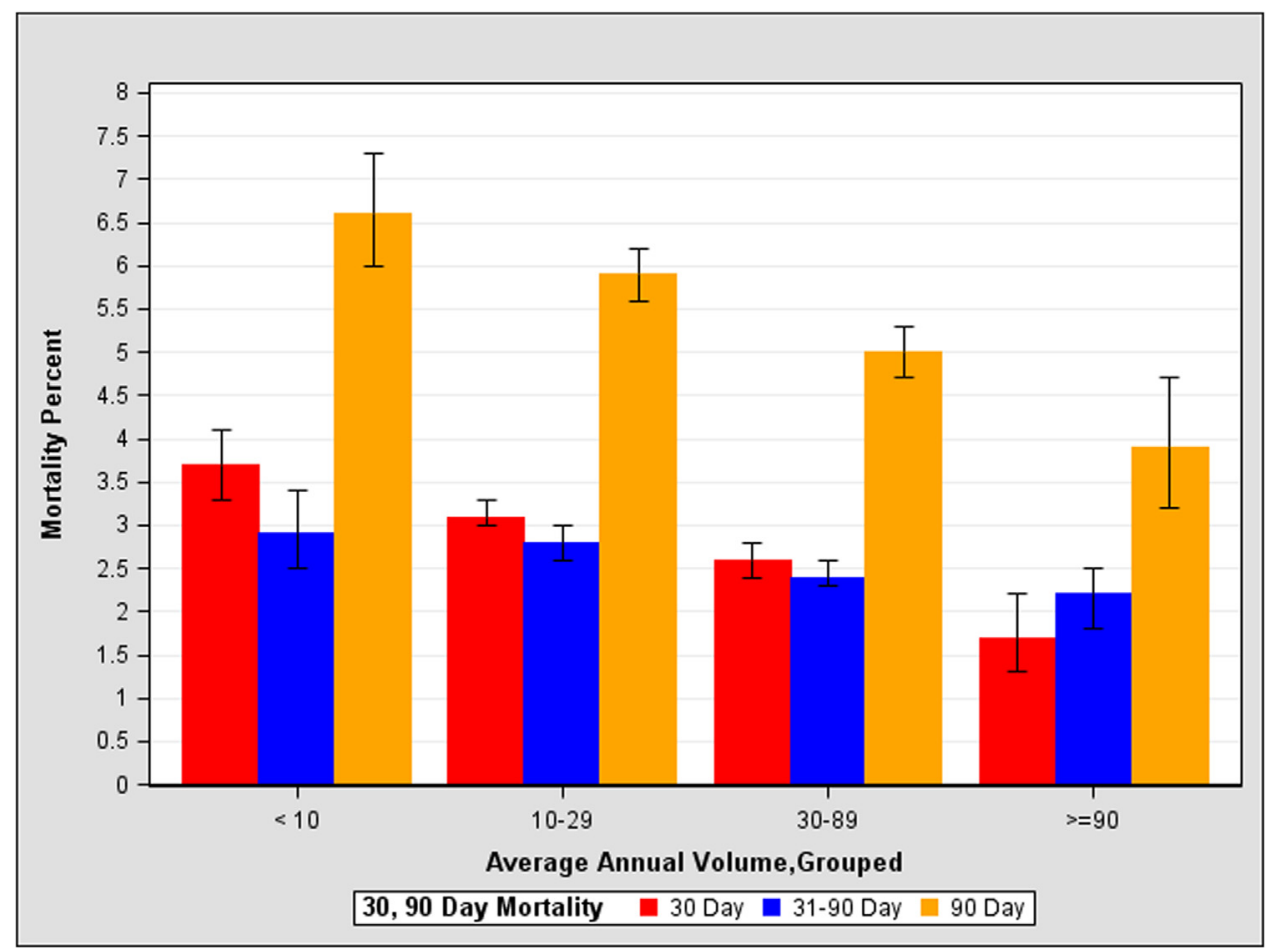

FIGURE 3. Thirty-day, conditional 90 -day, and 90 -day mortality rates, $95 \%$ confidence intervals, after major pulmonary resection by average annual hospital volume group (4 groups). 
TABLE 2. Unadjusted 30-day, conditional 90-day mortality rates by selected demographic, hospital, and clinical characteristics, and significant comorbid conditions diagnosed between 2007 and 2011*

\begin{tabular}{|c|c|c|c|c|}
\hline & \multicolumn{2}{|c|}{ 30-day mortality } & \multicolumn{2}{|c|}{ Conditional 90-day mortality $\dagger$} \\
\hline & $\begin{array}{c}\text { Mortality }(\%), \\
95 \% \text { confidence intervals }\end{array}$ & $\begin{array}{c}\text { Number of } \\
\text { deaths/number of cases }\end{array}$ & $\begin{array}{l}\text { Mortality }(\%), 95 \% \\
\text { confidence intervals }\end{array}$ & $\begin{array}{c}\text { Number of } \\
\text { deaths/number of cases }\end{array}$ \\
\hline All cases & $2.8(2.7-2.9)$ & $3389 / 121,099$ & $2.6(2.5-2.7)$ & $2968 / 114,905$ \\
\hline \multicolumn{5}{|l|}{ Average annual volume $\ddagger$} \\
\hline $0-9$ & $3.7(3.3-4.1)$ & $404 / 10,860$ & $2.9(2.5-3.4)$ & $303 / 10,278$ \\
\hline $10-29$ & $3.1(3.0-3.3)$ & $1363 / 43,409$ & $2.8(2.6-3.0)$ & $1146 / 41,035$ \\
\hline $30-89$ & $2.6(2.4-2.8)$ & $1384 / 53,155$ & $2.4(2.3-2.6)$ & $1238 / 50,615$ \\
\hline$\geq 90$ & $1.7(1.3-2.2)$ & $238 / 13,675$ & $2.2(1.8-2.5)$ & $281 / 12,977$ \\
\hline \multicolumn{5}{|l|}{ Age $\ddagger \S$} \\
\hline $18-49 y$ & $1.2(1.0-1.5)$ & $88 / 7140$ & $1.1(0.8-1.3)$ & $74 / 6857$ \\
\hline $50-59 y$ & $1.5(1.3-1.6)$ & $313 / 21,207$ & $1.5(1.4-1.7)$ & $311 / 20,330$ \\
\hline $60-69 y$ & $2.2(2.0-2.3)$ & $911 / 41,877$ & $2.1(2.0-2.3)$ & $853 / 40,009$ \\
\hline $70-79 y$ & $3.7(3.5-3.9)$ & $1483 / 39,919$ & $3.3(3.1-3.5)$ & $1239 / 37,570$ \\
\hline$\geq 80 \mathrm{y}$ & $5.4(4.9-5.9)$ & $594 / 10,956$ & $4.8(4.4-5.3)$ & $491 / 10,139$ \\
\hline \multicolumn{5}{|l|}{$\operatorname{Sex} \ddagger, \S, \|$} \\
\hline Male & $3.7(3.5-3.9)$ & $2266 / 61,367$ & $3.5(3.3-3.7)$ & $4279 / 59,987$ \\
\hline Female & $1.9(1.7-2.0)$ & $1122 / 59,700$ & $1.7(1.6-1.8)$ & $2082 / 58,330$ \\
\hline Unknown & $2.7(2.4-3.1)$ & $192 / 6986$ & $2.4(2.0-2.8)$ & $159 / 6610$ \\
\hline \multicolumn{5}{|l|}{ Stage $\ddagger, \S$} \\
\hline 0, I, occult & $2.3(2.2-2.5)$ & $1743 / 74,772$ & $1.8(1.7-1.9)$ & $1307 / 71,315$ \\
\hline II & $3.4(3.2-3.7)$ & $810 / 23,702$ & $3.2(3.0-3.5)$ & $724 / 22,280$ \\
\hline III & $3.8(3.4-4.1)$ & $653 / 17,321$ & $4.3(4.0-4.7)$ & $706 / 16,283$ \\
\hline IV & $4.6(3.8-5.3)$ & $144 / 3156$ & $7.5(6.5-8.4)$ & $220 / 2942$ \\
\hline Unknown & $1.8(1.2-2.4)$ & $39 / 2148$ & $0.5(0.2-0.9)$ & $11 / 2085$ \\
\hline \multicolumn{5}{|l|}{ Surgery type $\ddagger, \S$} \\
\hline Lobectomy/bilobectomy & $2.4(2.3-2.5)$ & $2726 / 113,150$ & $2.3(2.2-2.5)$ & $2521 / 107,799$ \\
\hline Pneumonectomy & $8.3(7.7-9.0)$ & $663 / 7949$ & $6.3(5.7-6.9)$ & $447 / 7106$ \\
\hline \multicolumn{5}{|l|}{ Neoadjuvant chemotherapy $\S$} \\
\hline Yes & $2.8(2.6-2.9)$ & $210 / 6971$ & $3.4(3.0-3.9)$ & $221 / 6479$ \\
\hline No & $3.0(2.6-3.5)$ & $3179 / 114,128$ & $2.5(2.4-2.7)$ & $2747 / 108,426$ \\
\hline \multicolumn{5}{|l|}{ Neoadjuvant radiation $\ddagger, \S$} \\
\hline Yes & $1.6(1.1-2.2)$ & $39 / 2418$ & $3.8(3.0-4.5)$ & $87 / 2318$ \\
\hline No & $2.8(2.7-3.0)$ & $3350 / 118,681$ & $2.6(2.4-2.7)$ & $2881 / 112,587$ \\
\hline
\end{tabular}

*Other variables significantly associated with 30-day and conditional 90-day mortality (not shown) include insurance, median income, census region, other primary cancers, diagnosis years, and selected Elixhauser comorbidities including congestive heart failure, cardia arrhythmias, pulmonary circulation disorders, peripheral vascular disease, hypertension, paralysis, other neurologic disorders, chronic pulmonary disease, renal failure, coagulopathy, obesity, weight loss, fluid and electrolyte disorders, blood loss anemia, deficiency anemia, depression. Diagnosis year, vascular disease, complicated diabetes, and peptic ulcer disease were also significant in 30-day mortality only. Race and AIDS were significant for conditional 90 -day mortality. $\dagger 90$-day mortality excludes deaths within the first 30 days. $\ddagger P \leq .05,30$-day mortality. $\S P \leq .05,90$-day mortality. $\| 32$ cases with unknown sex excluded.

data on Medicare hospitalizations as well as the Nationwide Inpatient Sample (NIS) to examine 2118 patients more than 65 years of age undergoing resection for non-small cell lung cancer between 1985 and 1996. They found a 3\% 30-day mortality rate at the highest volume hospitals compared with $6 \%$ at the lowest volume hospitals. They also found improved 5-year survival by $11 \%$ (44\% vs $33 \%$ ) favoring the highest volume hospitals.

Birkmeyer and colleagues ${ }^{8}$ used Medicare claims data and the NIS to examine 8 different major cancer resections from 1994 to 1999, including 75,563 patients undergoing lobectomy of the lung and 10,410 pneumonectomies. The mortality rate for lobectomy varied from $4.2 \%$ to $6.4 \%$ for the highest volume compared with the lowest volume hospitals, respectively, with an adjusted odds ratio for mortality of 0.70 (95\% CI, 0.60-0.81) favoring the highest volume group. An even larger overall difference in mortality of $6.4 \%(10.6 \%$ vs $17 \%)$ was found for pneumonectomy in the same extremes of volume groups.

Other studies have not found volume to be significantly related to outcome. ${ }^{12,14-17}$ Kozower and Stukenborg 9 examined 40,460 lung cancer resections performed at 436 hospitals using the 2007 NIS using 3 different methods. The overall in-hospital mortality rate was $2.94 \%$. Although they found a statistically significant relationship for volume when hospitals were categorized into quintiles, when hospital volume was expressed as a continuous variable, the association between volume and in-hospital mortality 
TABLE 3. Adjusted odds ratios, $* 95 \%$ confidence intervals for 30 -day and conditional 90-day mortality

\begin{tabular}{|c|c|c|}
\hline & \multicolumn{2}{|c|}{ Odds ratio, $95 \%$ confidence limits } \\
\hline & 30-day mortality & $\begin{array}{c}\text { Conditional } \\
\text { 90-day mortality }\end{array}$ \\
\hline \multicolumn{3}{|l|}{ Average annual volume } \\
\hline$\geq 90$ & 1.0 (reference) & 1.0 (reference) \\
\hline $30-89$ & $1.4(1.1-1.7)$ & $1.0(0.9-1.2)$ \\
\hline $10-29$ & $1.7(1.4-2.1)$ & $1.2(1.0-1.4)$ \\
\hline $0-9$ & $2.1(1.7-2.6)$ & $1.3(1.1-1.6)$ \\
\hline \multicolumn{3}{|l|}{ Age group } \\
\hline $18-49$ y (reference) & 1.0 (reference) & 1.0 (reference) \\
\hline $50-59$ y & $1.2(0.9-1.5)$ & $1.4(1.1-1.9)$ \\
\hline $60-69$ y & $1.9(1.5-2.4)$ & $2.0(1.6-2.6)$ \\
\hline $70-79$ y & $3.3(2.6-4.2)$ & $3.2(2.5-4.1)$ \\
\hline$\geq 80 \mathrm{y}$ & $5.2(4.1-6.7)$ & $5.1(3.9-6.6)$ \\
\hline \multicolumn{3}{|l|}{ Sex } \\
\hline Female & 1.0 (reference) & 1.0 (reference) \\
\hline Male & $1.6(1.5-1.8)$ & $1.8(1.6-1.9)$ \\
\hline \multicolumn{3}{|l|}{ Stage } \\
\hline $0, \mathrm{I}$, occult & 1.0 (reference) & 1.0 (reference) \\
\hline II & $1.3(1.2-1.4)$ & $1.6(1.5-1.8)$ \\
\hline III & $1.4(1.3-1.6)$ & $2.3(2.0-2.5)$ \\
\hline IV & $1.9(1.6-2.3)$ & $4.5(3.9-5.3)$ \\
\hline Unknown & $1.2(0.8-1.6)$ & $0.4(0.2-0.8)$ \\
\hline \multicolumn{3}{|l|}{ Surgery type } \\
\hline Lobectomy/bilobectomy & 1.0 (reference) & $1.5(1.3-1.7)$ \\
\hline Pneumonectomy & $3.7(3.4-4.1)$ & $2.3(2.1-2.6)$ \\
\hline \multicolumn{3}{|l|}{ Neoadjuvant radiation $\dagger$} \\
\hline No & 1.0 (reference) & 1.0 (reference) \\
\hline Yes & $0.5(0.3-0.7)$ & $1.0(0.8-1.3)$ \\
\hline \multicolumn{3}{|l|}{ Neoadjuvant chemotherapy } \\
\hline No & 1.0 (reference) & 1.0 (reference) \\
\hline Yes & $1.3(1.1-1.5)$ & $1.2(1.1-1.4)$ \\
\hline \multicolumn{3}{|c|}{$\begin{array}{l}\text { *All variables significant at } P<.05 \text { unless otherwise indicated. Other variables not } \\
\text { shown but included in the model: race, median income, insurance, census division, } \\
\text { previous cancers, diagnosis year, and the following Elixhauser comorbid conditions: } \\
\text { congestive heart failure, cardiac arrhythmias, pulmonary circulation disorders, } \\
\text { hypertension, paralysis, other neurologic disorders, chronic pulmonary disease, renal } \\
\text { failure, peptic ulcer disease, coagulopathy, weight loss, fluid and electrolyte } \\
\text { disorders, deficiency anemia, alcohol abuse, depression. } \dagger \text { Not significant, conditional } \\
\text { 90-day mortality. }\end{array}$} \\
\hline
\end{tabular}

disappeared. They concluded that hospital lung cancer volume is not a predictor of mortality and should not be used as a measure of quality. They stated that the most important predictors of mortality after lung cancer resection were patient age and comorbidities. Finlayson and colleagues $^{11}$ reported a significant relationship between hospital volume and operative mortality for lobectomy but not pneumonectomy. Freixinet and colleagues ${ }^{12}$ found no effect of volume on outcomes in a Spanish multicenter study of 2994 cases. Begg and colleagues ${ }^{13}$ did not find a link between higher volume and lower mortality for pneumonectomy using the SEER database.

Kozower and Stukenborg ${ }^{9}$ suggest that many previous studies of volume and mortality are statistically flawed by the use of arbitrary defined volume categories. They also point out the weakness of using administrative data. They suggest that the very large numbers in large databases make statistical significance easy to accomplish, but that not all statistically significant results are clinically significant. We believe that the 2-fold increase in adjusted odds ratio for 30-day mortality seen in the present study comparing the lowest with the highest volume groups is both statistically significant and clinically significant, and that the larger number of cases from a larger number of institutions allowed us to identify this significant effect.

The overall mortality rate within 30 days of a major lung resection in the NCDB from 2007 to 2011 was $2.8 \%$, from more than $1200 \mathrm{CoC}$-approved hospitals across the United States. This is lower than the mortality rate from the previous large studies ${ }^{6-9}$ and lower than reported from 2 European thoracic surgery units in $2007,{ }^{15}$ but is higher than the $2.2 \%$ mortality rate reported (in-hospital or within 30 days) in the Society of Thoracic Surgeons database which examined 18,800 resections for lung cancer (including wedge resections and segmentectomies) from 2002 to 2008 performed by a more select group likely to be academic general thoracic surgeons at 111 hospitals. ${ }^{16}$

The 30-day mortality rate of $4.1 \%$ for the group more than 70 years of age in the current study is lower than the $4.2 \%$ mortality rate reported at the highest volume hospitals by Birkmeyer and colleagues ${ }^{8}$ just a decade before (in a Medicare population). Historically, the Lung Cancer Study Group reported $7.1 \%$ mortality for patients 70 years of age and older in $1983 .{ }^{17}$ The low rate of pneumonectomy in this study $(7 \%)$, and the decline in the use of pneumonectomy over the years, has clearly helped to lower the overall surgical mortality after major pulmonary resection, but the mortality rate for lobectomy has also significantly declined over time as well, not just at the biggest and highest volume hospitals but also when examined in all CoC-accredited institutions across the United States entering data in the NCDB.

The observation that the overall 90-day conditional mortality rate $(2.6 \%)$ in all patients was nearly as high as the overall 30 -day mortality rate $(2.8 \%)$ after surgical resection, leading to a $5.4 \%$ overall 90 -day mortality after major pulmonary resection, warrants further study. Powell and colleagues ${ }^{18}$ have also recently reported that $3 \%$ mortality at 30 days nearly doubled to $5.9 \%$ at 90 days in an examination of 10,991 patients from a National Lung Cancer Audit of English patients. The found that the features of patients who died in the first 30 days were no different from those who died between 31 and 90 days postoperatively. They suggest that 90-day mortality risk, not just 30-day mortality, should be considered preoperatively, and we would agree. $\mathrm{Hu}$ and colleagues ${ }^{14}$ reported almost double mortality $(3 \%-4 \%$ to $6.9 \%)$ in 11,787 patients who underwent resection comparing 30 days with 90 days in the linked SEER-Medicare Registry from 2006 
TABLE 4. Unadjusted mortality rates, and risk-adjusted odds ratios by annual volume for lobectomy/bilobectomy only and pneumonectomy only, 2007 to 2011

\begin{tabular}{|c|c|c|c|c|}
\hline & \multicolumn{2}{|c|}{ 30-day mortality* } & \multicolumn{2}{|c|}{ Conditional 90-day mortality $\dagger$} \\
\hline & $\begin{array}{c}\text { Lobectomy/bilobectomy } \\
\text { only }(\mathbf{n}=113,150 \\
2726 \text { deaths })\end{array}$ & $\begin{array}{l}\text { Pneumonectomy } \\
\text { only }(n=7949 ; \\
663 \text { deaths })\end{array}$ & $\begin{array}{c}\text { Lobectomy/bilobectomy } \\
\text { only }(\mathbf{n}=107,799 \\
2521 \text { deaths })\end{array}$ & $\begin{array}{c}\text { Pneumonectomy } \\
\text { only }(n=7106 ; \\
447 \text { deaths }) \\
\end{array}$ \\
\hline Overall mortality rate $(\%)$ & $2.4(2.3-2.5)$ & $8.3(7.7-9.0)$ & $2.3(2.2-2.4)$ & $6.3(5.7-6.9)$ \\
\hline \multicolumn{5}{|l|}{ Annual volume $\ddagger$} \\
\hline$<10$ & $3.2(2.9-3.6)$ & $10.9(8.4-13.5)$ & $2.7(2.3-3.1)$ & $6.8(4.8-8.8)$ \\
\hline $10-29$ & $2.7(2.6-2.9)$ & $9.1(8.0-10.3)$ & $2.5(2,4-2.7)$ & $6.9(5.8-7.9)$ \\
\hline $30-89$ & $2.2(2.0-2.4)$ & $8.1(7.1-9.0)$ & $2.2(2.0-2.4)$ & $5.9(5.0-6.8)$ \\
\hline$\geq 90$ & $1.5(1.1-1.9)$ & $5.4(4.0-6.7)$ & $1.9(1.5-2.3)$ & $5.8(4.3-7.3)$ \\
\hline \multicolumn{5}{|l|}{ Annual volume $\ddagger$} \\
\hline$<30$ & $2.8(2.7-3.0)$ & $9.5(8.5-10.5)$ & $2.6(2.4-2.7)$ & $6.8(5.9-7.8)$ \\
\hline$\geq 30$ & $2.1(1.9-2.2)$ & $7.5(6.6-8.3)$ & $2.1(2.0-2.3)$ & $5.9(5.1-6.6)$ \\
\hline \multicolumn{5}{|l|}{ Adjusted odds ratios $\S$} \\
\hline \multicolumn{5}{|l|}{ Annual volume $\ddagger$} \\
\hline$\geq 90$ & 1.0 (reference) & 1.0 (reference) & 1.0 (reference) & 1.0 (reference) \\
\hline$<10$ & $2.0(1.6-2.6)$ & $2.2(1.5-3.2)$ & $1.3(1.1-1.7)$ & $1.2(0.8-2.0)$ \\
\hline $10-29$ & $1.6(1.3-2.0)$ & $1.7(1.3-2.4)$ & $1.2(1.0-1.5)$ & $1.2(0.8-1.7)$ \\
\hline $30-89$ & $1.3(1.1-1.6)$ & $1.5(1.1-2.1)$ & $1.1(0.9-1.3)$ & $1.1(0.9-1.3)$ \\
\hline \multicolumn{5}{|l|}{ Annual volume $\ddagger$} \\
\hline$\geq 30$ & 1.0 (reference) & 1.0 (reference) & 1.0 (reference) & 1.0 (reference) \\
\hline$\leq 30$ & $1.4(1.2-1.5)$ & $1.3(1.1-1.5)$ & $1.2(1.1-1.3)$ & $1.2(1.0-1.5)$ \\
\hline
\end{tabular}

to 2010. Mortality after 30 days and after hospital discharge up to 90 days postoperatively was studied using the Rotterdam Cancer Registry; 3.6\% 30-day mortality and $6.8 \%$ 90-day mortality was reported between 2006 and $2008 .{ }^{19}$

Some of the decrease in 30-day mortality seen in the current study likely has resulted from the increased ability to support critically ill patients postoperatively, delaying some postoperative mortality beyond the traditional 30-day period often used to report operative mortality. A broadened definition of operative mortality to include 30-day and in-hospital mortality during the initial admission will still not capture patients discharged to hospice care more than 30 days after surgery or who die after discharge. Even the highest volume and highest performing hospitals still had a combined 90-day mortality rate of $3.9 \%$, almost 1 death for every 25 patients resected. The proportion of the conditional 90-day mortality that occurred in the current study after discharge from the initial hospitalization for pulmonary resection versus during a prolonged initial hospitalization is not known.

Strengths of the current study of more than 120,000 patients treated at $\mathrm{CoC}$-approved institutions include the use of data from the NCDB entered by Certified Tumor Registrars at each institution (not administrative data) and the inclusion of only major pulmonary resections (lobectomy, bilobectomy, and pneumonectomy). Although the NCDB is a hospital-based and not a population-based cancer registry, the ability to capture more than $80 \%$ of all new lung cancer cases treated in the United States each year, at both large and small institutions, academic and community-based, allows a representative analysis and reporting of care delivery across the United States to all CoC-approved programs.

Missing data on 30-day mortality for 3300 cases, although only $2.7 \%$ of all resections over this 5 -year period, are a weakness of this study. A major proportion of the cases missing mortality data were treated in the final year of the study (2011). The equal distribution of cases missing data across the annual hospital volume groups, and the equivalent mortality rate excluding the 2011 data completely, suggest that the overall conclusions would not be different. Another weakness relates to the Elixhauser comorbidity groups taken from ICD-9-CM codes. It is not always clear which ICD-9-CM codes were present on admission versus those that might have developed postoperatively or as a result of complications, such as coagulopathy.

The doubling of the chance of death within 30 days after a major pulmonary resection from the rate of $1.7 \%$ at the highest volume hospitals to $3.7 \%$ at those hospitals performing 9 or fewer major resections per year (risk-adjusted odds ratio for mortality, 2.1; 95\% CI, 1.7-2.6) represents a variation in outcomes as well as an opportunity for improvement in the care of these patients with potentially curable lung cancer. A significant percentage of patients were 
treated at hospitals with an annual volume of less than 10 ( $9 \%$ of all resections) or an annual volume of less than 30 ( $45 \%$ of resections).

Given the relationship of volume to outcomes, and in the interest of continued and continuous quality improvement, hospitals should be aware of their annual volume for major pulmonary resection and their institutional mortality associated with those resections over time (at both 30 days and 90 days) compared with national data. Although our methodology and analysis did not allow us to identify an absolute break point or optimal minimum annual volume, our data suggest the more the better and that mortality continues to decline with increasing volume. Benchmarking outcomes against those institutions performing more than 30 resections per year would attempt to address much of the variation currently seen, and has practical value. Those hospitals with low volume and/or high mortality can then develop strategies to address the differences in outcomes for their patients compared with those treated at higher volume institutions with lower mortality. Specific strategies to address low volume and/or high mortality of major pulmonary resection are beyond the scope of this report, but should be explored through future efforts and investigation. To aid this process of continuous quality improvement, the $\mathrm{CoC}$ now reports annual hospital volume for major pulmonary resection, and 30-day mortality for those resections, to all CoC-approved programs using NCDB data submitted by the hospitals on an annual basis, as part of the Cancer Quality Improvement Program, and starting in 2014 also plans to report 90-day mortality.

\section{References}

1. Luft HS, Bunker JP, Enthoven AC. Should operations be regionalized? The empirical relation between surgical volume and mortality. $N$ Engl J Med. 1979;301:1364-9.

2. Bilimoria KY, Stewart AK, Winchester DP, Ko CY. The National Cancer Data Base: a powerful initiative to improve cancer care in the United States. Ann Surg Oncol. 2008;15:683-90.

3. Elixhauser A, Steiner C, Harris DR, Coffey RM. Comorbidity measures for use with administrative data. Med Care. 1998;36:8-27.

4. Lieffers JR, Baracos VE, Winget M, Fassbender K. A comparison of Charlson and Elixhauser comorbidity measures to predict colorectal cancer survival using administrative health data. Cancer. 2011;117:1957-65.

5. Southern DA, Quan H, Ghali WA. Comparison of the Elixhauser and Charlson/ Deyo methods of comorbidity measurement in administrative data. Med Care. 2004; 42:355-60.

6. Romano PS, Mark DH. Patient and hospital characteristics related to in-hospital mortality after lung cancer resection. Chest. 1992;101:1332-7.

7. Bach PB, Cramer LD, Schrag D, Downey RJ, Gelfand SE, Begg CB. The influence of hospital volume on survival after resection for lung cancer. N Engl J Med. 2001;345:181-8.

8. Birkmeyer JD, Siewers AE, Finlayson EV, Stukel TA, Lucas FL, Batista I, et al. Hospital volume and surgical mortality in the United States. N Engl J Med. 2002; 346:1128-37.

9. Kozower BD, Stukenborg GJ. The relationship between hospital lung cancer resection volume and patient mortality risk. Ann Surg. 2011;254:1032-7.

10. Hannan EL, Radzyner M, Rubin D, Dougherty J, Brennan MF. The influence of hospital and surgeon volume on in-hospital mortality for colectomy, gastrectomy, and lung lobectomy in patients with cancer. Surgery. 2002;131:6-15.

11. Finlayson EVA, Goodney PP, Birkmeyer JD. Hospital volume and operative mortality in cancer surgery. Arch Surg. 2003;138:721-5.
12. Freixinet JL, Julia-Serda G, Rodriguez PM, Santana NB. Rodriguez de Castro F, Fiuza MD, Lopez-Encuentra A. Hospital volume: operative morbidity, mortality and survival in thoracotomy for lung cancer. A Spanish multicenter study of 2994 cases. Eur J Cardiothorac Surg. 2006;29:20-5.

13. Begg CB, Cramer LD, Hoskins WJ, Brennan MF. Impact of hospital volume on operative mortality for major cancer surgery. JAMA. 1998;280:1747-51.

14. Hu Y, McMurray TL, Wells KM, Isbell JM, Stukenborg GJ, Kozower BD Postoperative mortality is an inadequate quality indicator for lung cancer resection. Ann Thorac Surg. 2013;97:973-9.

15. Brunelli A, Morgan-Hughes NJ, Refai M, Salati M, Sabbatini A, Rocco G Risk-adjusted morbidity and mortality models to compare the performance of two units after major lung resections. J Thorac Cardiovasc Surg. 2007;133: 88-96.

16. Kozower BD, Sheng S, O'Brien SM, Liptay MJ, Lau CL, Jones DR, et al STS database risk models: predictors of mortality and major morbidity for lung cancer resection. Ann Thorac Surg. 2010;90:875-83.

17. Ginsberg RJ, Hill LD, Eagan RT, Thomas P, Mountain CF, Deslauriers J, et al, Modern thirty-day operative mortality for surgical resection in lung cancer J Thorac Cardiovasc Surg. 1983;86:654-8.

18. Powell HA, Tata LJ, Baldwin DR, Stanley RA, Khakwani A, Hubbard RB Early mortality after surgical resection for lung cancer: an analysis of the English National Lung cancer audit. Thorax. 2013;68:826-34.

19. Damhuis RAM, Wijnhoven BPL, Plaisier PW, Kirkels WJ, Kranse R, van Lanschot JJ. Comparison of 30-day, 90-day and in-hospital postoperative mortality for eight different cancer types. Br J Surg. 2012;99:1149-54.

\section{Discussion}

Dr Cameron D. Wright (Boston, Mass). Thank you, Dr Pezzi, for a wonderful, very clear presentation. Using the National Cancer Database to form a robust data set of 120,000 patients who had a lung cancer resection, the authors have demonstrated a modest, and I underline that word modest, volume/performance relationship with an absolute mortality difference of $2 \%$ between volumes less than 10 and greater than 90 . The usual risk factors for mortality were identified such as age. The authors picked a somewhat arbitrary annual hospital volume of 30 without a receiver operating characteristic curve analysis to define low volume hospitals that they suggest should be carefully monitored in terms of their results. Their volume/performance relationship reporting is not new, and although this has been somewhat debated in the literature, most reports do indeed suggest there is a modest relationship, as this report does.

Of more interest to me is the substantial increase in mortality at 90 days, essentially doubling the 30-day mortality. This report corroborates 2 very recent reports that also suggested doubling of lung cancer mortality at 90 days, and in fact the mortality for pneumonectomy at 90 days was a very sobering $14.6 \%$. It begs the question, are we misleading our patients when we counsel them about their perioperative risk? We need to learn more about what happens to our patients in this vulnerable period of time after they are discharged to see if we can mitigate that risk. Obviously this report cannot do that, but it certainly leads to an interesting hypothesis and more work to be done. I have 2 questions.

First, why is there more volume/performance effect in the first 30 days versus the conditional 90 days? The odds ratio drops from 2 to a just slightly significant 1.3 .

Dr Pezzi. Thank you, Dr Wright, for those comments and for your first question, which is an excellent question. As far as the reasons why we see a greater effect of volume on mortality during the first 30 days than between 30 and 90 days, we honestly do not know, but I wonder if this might suggest that some surgeonor institution-related factors are driving the 30-day mortality, 
whereas perhaps some patient-related or patient disease-related factors, such as their tumors or comorbidities, are more responsible for mortality between 30 and 90 days? We do still see an effect on mortality between 30 and 90 days, but it is, as you pointed out, significantly less. But this is just a hypothesis. I certainly agree with you that we need to further study why these patients are dying between 30 and 90 days, and hopefully that will shed some light on what we can do to affect that mortality.

Dr Wright. And trending along that same line, where there is a volume/performance relationship for pneumonectomy for the 30-day mortality, there is none for the conditional 90-day mortality. Given the very large morbidity and mortality of pneumonectomy, in which another $6 \%$ die in that 60-day window, is this just a matter of small numbers? Why was that not significant? What is your hypothesis there?

Dr Pezzi. Again, the overall magnitude we saw across the board seemed to decline between 30 and 90 days compared with the first 30 days, and perhaps we are dealing with small numbers, although we did have 8000 pneumonectomies in this study, but perhaps it is just small numbers. Again, I wonder if it could be patient-related factors. I think as surgeons, we want to take responsibility for all mortality of our patients, not just within 30 days, but even if a patient dies 2 months later or 3 months later, I think we would feel that somehow our operation might have contributed or had something to do with that.

However, I think the longer we get out from the date of surgery, it is possible that other factors beyond our control that are not completely surgeon- or institution-related may be at play here, and perhaps that is why we see a diminishing effect of volume the further we get out from the date of surgery. This is just my best guess to try to address your question.

Thank you very much for your comments and questions.

Dr Thomas K. Waddell (Toronto, Ontario). I enjoyed your presentation. I want to follow up on Dr Wright's question about why the conditional mortality is not different in different size of hospitals. Two questions to think about.

Are you able to describe any aspect of hospitals that have better versus worse outcomes in that conditional mortality and are you able to see postdischarge mortality as opposed to conditional mortality based simply on the time points?

And the second question to think about, you presented beautifully the evolution of 30-day mortality over time. Do you have any data about the evolution of conditional mortality over time? Is this also getting better or has it always been the same magnitude of problem?

Dr Pezzi. To address your last question first, I think it is an excellent question, and that is, we have traditionally defined surgical mortality as 30 days or during the initial admission, and so we do not have too much data on 90-day mortality over the decades. And so I guess the question that comes to mind is: has this mortality been there all along and we just did not notice it, or is there something different now that we are essentially pushing some of the mortality that used to occur in the first 30 days beyond 30 days? In talking to our surgical intensivists, they can keep sick patients alive longer, perhaps beyond 30 days, but maybe not beyond 90 days. And so are we just pushing on some of that mortality?

You talked about discharges. These are actually 30 and 90 days and have nothing to do with hospitalization. We really did not look at time of discharge or various hospitalizations. We are just looking at crude survival at 30 and 90 days.

I think this is important, because at my own institution, if a patient is doing poorly and they are not going to make it, and it looks bad, and they have been on a ventilator for 4 weeks, a lot of times they get sent to hospice and they are considered discharged at that point and they are readmitted to hospice. And so they would not be picked up as either a 30-day mortality or an initial hospitalization mortality. They are considered discharged. So I think that is an excellent point you bring up.

I hope I answered your question.

Dr Tomasz Grodzki (Szczecin, Poland). I have 1 short question. Why did you decide that 90 cases per year is high volume? European standards consider more than 200 as high volume. It means that it is 2 cases per week. If you have 3 surgeons, every single surgeon is doing less than 1 case per week. It is not a high volume.

Dr Pezzi. Thank you. That is an excellent question. It was, as Dr Wright pointed out and I would acknowledge, a weakness, that it was somewhat arbitrary how we divided our volume groups. I would point out that only 21 hospitals were in that high volume group out of 1200 . So to set the bar even higher would have led to an even smaller number of hospitals.

Dr Mark J. Krasna (Neptune, NJ). Congratulations, Chris, to you and the authors from the Commission on Cancer. I believe 1 of the points also to take away from here, if I am not mistaken, is that the Commission on Cancer data are currently reported back to the hospitals, and it is not specified whether the surgeons performing the operations were thoracic surgeons versus nonthoracic surgeons. I do think it would be very interesting going forward in a prospective fashion if you could get granular data to identify not only the high volume from the low volume hospitals but also identify hospitals where most of the surgery was done by thoracic surgeons versus general surgeons.

I know in the past we have heard many papers about this, but I do think using the NCDB data, we could maybe put in that granularity and ask for that information going forward. I think it is a very good start.

Dr Pezzi. Thank you very much. Yes, the NCDB currently is a hospital-based registry, but they will be using National Provider Identifier (NPI) numbers to report surgeon-specific data going forward. It was not available in this data set, but in the future that will be available using NPI numbers.

Dr Scott Swanson (Boston, Mass). Nice paper. One quick question. You may have said it and I missed it. Why is 90 days the max? Do we know what happens at 4 months, 6 months, 1 year? Does it flatten out and do you know that?

Dr Pezzi. That is an excellent question. We did not look at that but I think we should. 